\title{
The Effect of Using Blended Learning in Teaching English on Direct and Deferred Achievement of Primary School Students
}

\author{
Abdallah Nabih Mustafa Banihani ${ }^{1}$ \\ ${ }^{1}$ Jadara University, Jordan \\ Correspondence: Abdallah Nabih Mustafa Banihani, Jadara University, Jordan.
}

Received: February 1, 2021

Accepted: March 12, 2021

Online Published: March 19, 2021

doi:10.5539/ibr.v14n4p50

URL: https://doi.org/10.5539/ibr.v14n4p50

\begin{abstract}
The study aimed at recognizing the effect of using integrated learning methods in teaching English on immediate and later achievement for primary phase students. The study followed a quasi-experimental method by using an experimental group, which learned English through integrated learning and a controlled group, which learned the same subject by using the traditional way. To achieve the study's objectives, the researcher prepared an achievement test. The validity and reliability of the test have been checked by introducing it to a group of specialized teachers in addition to finding Cronbach's alpha value, which worked out at $(0,627)$. After data collection has been completed, the arithmetic means of the immediate achievement test and later achievement test have been calculated. The results indicate that there are statistically significant differences in the achievement of the primary phase in favor of the experimental group, which has been taught the English subject by integrated learning method. The study recommends that it is necessary to apply an integrated learning strategy since it is effective in students' scientific achievement, and improving motivation for learning, and considering the rules of the integrated educational process to train the teaching staff to apply integrated learning.
\end{abstract}

Keywords: integrated learning, direct achievement, deferred achievement, controlled group, and experimental group

\section{Introduction to the Study}

\subsection{General Background of the Study}

The current era is characterized by many rapid changes, which necessitates a review of teaching methods(Abu Musa \&Al-sous,2010) to ensure the extent to which they keep pace with the new developments and contemporary trends, and among these methods is the use of computers in education, as it has become seen as the magic solution to all human problems in various fields, which led researchers in the field of education to follow issues related to the use of computers in the educational process in various aspects, starting with managing and supervising educational institutions (Abu Musa \& Al-Sous, 2010);(Mustafa, 2011). Blended learning is one of the contemporary trends in education, and one of the new features in the $21^{\text {st }}$ century. Blended learning can be described as an educational method in which more than one means of transferring knowledge and experience to learners is used to achieve the best possible learning outcomes. Therefore, this model combines the advantages of e-learning and classroom learning advantages. This method is based on the approach of integration between traditional learning and e-learning ;( Awad, 2010); (Heinze \& Procter, 2004).

\subsection{Introduction to the Study Problem}

The English language is one of the most important subjects in the basic education stage, as it has become the first global language and the most widespread in the world, being the language of the modern age, science, technology and scientific research (Boyle, 2005); (Singh, 2003). Therefore, special methods must be followed through which effective thinking skills are developed among learners of this language at an early age and in the basic education stage. Computerized educational programs have a special benefit from the educators' point of view, as they help the child to think and learn in a better way. Blended learning uses computers in a way that combines teaching styles and computer-aided learning, such as teaching problem-solving, dialogue, training, simulation and educational games, in addition to e-learning via the information network or the Internet and its data such as e-mail and chat rooms, as well as the possibility of practicing self-learning, so that it makes all of the above a brilliant program that supports the role of the teacher and makes it more effective and allows him/her to become the director of the 
educational process and make it accessible and effective (Ausburn, 2004); (Creason, 2005); (Steve, 2001).

The Jordanian Ministry of Education has taken an early interest in blended learning, as the e-learning initiative was launched in the year (2002) as part of the Education Development Project, which aims to provide e-learning at the school and university levels. Jordan has made important achievements in this regard in cooperation with the company Cisco and several government agencies, international bodies, and civil society organizations, as it connected more than $(1,200)$ schools out of $(3,200)$ government schools to the national schools' network, and computer laboratories have been established in more than $(2,500)$ schools since the start of the project (Al-Fiqi, 2011); (Al-Aifari, 2010); (Al-Shammari, 2007).

\subsection{Problem of the Study}

The English language course is in dire need of teaching strategies that lead to eliminating the preservation of knowledge contained in the curriculum, and thus the teacher's role changes from teaching that knowledge to helping students generate useful and applicable knowledge; in this context, the objectives of educational policy in Jordan emphasize the adoption of the latest technologies reached by the world, the provision of an internal information network in schools, and the provision of computers and learning resource centers. Therefore, the Ministry of Education has updated curricula and textbooks and has taken an interest in computers and blended teaching as a result of the challenges that the world has witnessed in political, economic, educational, and social dimensions, which formed in various dimensions and to face these challenges, it is imperative to make optimal use of modern technical methods and means in the educational process, including blended learning, which in turn may help the learner increase his effectiveness and level of achievement (Salem, 2004); (Dikeidek, 2011);( Abu Musa \& Al-Sous, 2010).

Hence, the need to recognize the impact of the use of blended learning in teaching English on the direct and deferred achievement of primary school students rose, and accordingly, the study problem was formulated in the framework of a methodology represented by the following questions:

1. What is the effect of using the blended learning method in teaching English on the direct achievement of primary school students?

2. What is the effect of using the blended learning method in teaching English on the deferred achievement of primary school students in Jordanian private schools?

\subsection{Objectives of the Study}

In light of the study problem and its questions, the study objectives were formulated as follows:

- Main objectives

- Identifying the effect of using the blended learning method in teaching English on the direct achievement of primary school students in Jordanian private schools,

- Identifying the effect of using the blended learning method in teaching English on the deferred achievement of primary school students in Jordanian private schools.

The main objectives are divided into the following sub-objectives:

- Shedding light on the theory of blended learning,

- Reaching results through which recommendations are made to help educational organizations apply the blended learning method in a scientific, systematic manner that has positive effects on the achievement level of primary school students.

\subsection{Study Variables}

- $\quad$ First: Independent Variable $\square \quad$ Blended Learning

- Second: Dependent Variables $\square *$ Direct Achievement

* Deferred Achievement

\subsection{Study Hypotheses}

Based on the independent and dependent study variables, the study hypotheses were formulated in the nihilistic form as follows:

The first main hypothesis:

- $\mathrm{H}_{01}$ : There is no statistically significant effect of the blended learning method on the direct achievement of primary school students in Jordanian private schools. 
The second main hypothesis:

- $\mathrm{H}_{02}$ : There is no statistically significant effect of the blended learning method on the deferred achievement of primary school students in Jordanian private schools.

\subsection{Study Implications}

This study presents theoretical and practical frameworks on the blended learning method, which results in raising effects and implications on two main levels, which are as follows:

- Theoretical frameworks: This study helps researchers and educational experts to generate ideas and perceptions for preparing educational studies and research in terms of methodology, target group, and countries, in addition to the possibility of linking it with fields and knowledge sciences, which leads to reducing the gap in the educational research field.

- Practical frameworks: The study provides recommendations for decision-makers in educational organizations to help them know the educational process based on blended learning, which helps to achieve the following:

1. Knowing the strengths and weaknesses in the application of the educational process based on blended learning, which helps to enhance the strengths and address weaknesses through successful, scientific means based on correct and clear methodological foundations and standards,

2. Helping educators develop more effective models of educational strategies that contribute to teaching the English language,

3. Creating an interactive atmosphere that contributes to teaching English to students,

4. Increasing interaction between students and teachers,

5. Moving away from indoctrination and teaching students how to learn,

6. Facilitating English language learning by focusing on the blended learning process and employing it in the classroom

\subsection{The Economic Side of Study}

This study helps to indicate a new strategy in the educational system, which is the blended learning strategy, which studies have proven its importance in improving the quality of the educational process and its outputs. This helps educational institutions that aim to achieve a profit to follow this strategy in a way that helps raise the level of students, which encourage current students to stay and attract new students in a way that achieves profit and expansion of the educational institution. This is reflects positively on its competitive advantage and its sustainability in educational environment.

\section{Literature Review}

\subsection{The Concept of Blended Learning}

The exchange of information and experiences has become a basic feature of this era, and learning in particular had to face it and develop according to these rapid and modern changes and developments; thus, many important technological innovations appeared that help and keep pace with these developments and contribute to solving many educational problems, and blended education is an integrated system that combines the traditional method of learning face to face with e-learning to guide and assist the learner during each stage of learning as one of the modern approaches based on the use of educational technology in designing new educational situations (Al-Feki, ,2011).

Heinze \& Procter (2004) define it as a type of learning that uses an effective set of multiple presentation methods, teaching methods, and learning styles that facilitate the learning process and builds on the basis of a merging the traditional method, in which students meet their teachers face-to-face, and the e-learning method inside the study halls.

As for Qustandi (2007), he defines it as the use of modern technology in teaching without abandoning the usual educational reality and attending the classroom. The focus is on direct interaction inside the classroom by using modern communication mechanisms such as the computer and the Internet. This type of learning can also be described as how information, educational attitudes and experiences that are provided to the learner through the various means provided by modern technology or information technology are organized.

\subsection{Blended Learning Models}

There are many models related to the blended learning process, ranging from simple to complex, but they all have 
in common the use of modern media, activities, technologies, learning experiences and traditional teaching methods. The following is an illustration of the blended learning models as pointed out by ( Brame ,2013), ( Beavers ,2014), and( Smith,2016).

\section{First: Skill-Driven Learning Model}

This model combines self-paced learning with supporting teacher knowledge development through e-mail, discussion forums, and face-to-face learning with self-paced learning such as books and Internet-based courses. This learning is similar to a chemical reaction in which the interaction with the teacher acts as a catalyst for achievement to reach the reaction required to learn.

\section{Second: Trend-Driven Learning Model}

This model integrates diverse events and modes of presentation to develop specific behaviours that require learners to interact with each other; this requires a risk-free learning environment.

\section{Third: Competency-Driven Learning Model}

This model integrates performance support tools with knowledge management resources and consulting to develop specific competencies for capturing and imparting embedded knowledge that requires learners to interact with subject matter experts.

\subsection{The Components of Blended Learning}

The components of blended learning as indicated by( Moukali ,2012),( Huang \& Zhou ,2006), (Taha,2015), and (Al-Dasouqi ,2016) are the following:

First: Simultaneous Live Events

They are simultaneous teacher-led events in which learners participate at the same time as in virtual classes, and simultaneous live events are a major component of blended learning. For many learners, nothing can replace direct communication and in order to be able to convey the effective live event, researcher John Keller states that there are three elements of motivation in his model:

- Attracting attention, and can happen when the teacher throws a question to the learners to think about and prepare for the learning process.

- Make the topic relevant to their real life, as it presents examples that are familiar to the learners while explaining how to apply what they are learning in reality.

- Confidence, the teacher clarifies to the students the expectations that are desired to be achieved from them and then gives them sufficient time to practice new skills; the learners' success in reaching the teacher's expectations by achieving those skills gives them confidence in their abilities and skills, and thus there is an incentive for more learning.

\section{Second: Self-Paced Learning Events}

They are the learning experiences that the learner completes individually based on his/her own speed and own time, such as chat-based training and CDs. Classifying asynchronous self-learning events has important value for the blended learning equivalent in order to obtain the maximum value of real action results from self-learning.

Third: Cooperation

It takes place in environments where learners communicate with others, for example: e-mail, internet chatting, and discussion forums. The power of live events or self-learning experience is incorporated when there is an opportunity to increase meaningful cooperation, as humans are social beings, and as the constructivist theory of learning assumes, humans develop themselves and new knowledge as a result of their social interactions with others. Cooperative learning also offers tremendous benefits that are not available through traditional learning to students. There are two types of cooperation that give effective results: cooperation between learners (peer-to-peer) and cooperation between learners and teacher (peer-to-mentor). The peer-to-peer cooperation provides an opportunity for learners to cooperate and discuss critical issues with other learners, while peer-to-mentor cooperation enables expert mentors to provide additional guidance to learners in the form of email tips, reminders, and suggested practice items.

Fourth: Evaluation

It is the measurement of learners' knowledge. Pre-evaluation comes before the live events or the self-learning events to determine the prior knowledge, and post-evaluation comes after the live events or the self-learning events in order to measure the learning gain, and it measures the effectiveness of all other events and forms. Evaluation is 
one of the most important components of blended learning for two reasons:

1. It enables learners to ascertain the content that they have already learned

2. It measures the effectiveness of all learning events and methods, etc.

Fifth: Performance Support Tools

It is the most important component of blended learning, as it ensures the survival and transmission of learning in the learning environment, and includes printable references, auxiliary works, and a personal digital assistant.

\subsection{Dimensions of Blended Learning}

The original use of the term "blended learning" was often linked simply to linking learning in the traditional classroom with e-learning activities. This term has evolved to include a set of dimensions of the blended learning program as referred to by (Al-Saeed, 2017), (Al-Dasouqi, 2016) and (Clement et al, 2016):

First: Blending Direct and Indirect Learning

Blended learning combines in its simplest forms direct and indirect learning, where direct learning means learning on the internet, and indirect learning takes place in the traditional classroom. An example of this type of blending is an educational program that provides learning materials and research resources on the Internet with customized educational sessions that take place inside the classroom and led by the teacher as the primary medium in the educational process.

Second: Blending Self-Paced and Cooperative Learning:

Self-learning means individual or on-demand learning that is managed and its pace is controlled by the individual, while cooperative learning means more dynamic communication between many learners, which facilitates the process of sharing knowledge.

Third: Blending Structured and Unstructured Learning:

Not all forms of learning refer to a formal or systematic learning program with content organized into a specific sequence such as chapters in a textbook. In fact, most learning that happens in a workplace happens informally, such as meetings, Internet conversations, and e-mail.

Fourth: Blending Custom and Off-the-Shelf Content:

Custom content is content that we build ourselves and off-the-shelf content is less expensive than custom content. Standards such as SCORM open the door to more flexibility in blending custom and off-the-shelf content, thus improving user experience, and minimizing cost as much as possible.

\section{Methodology of the Study}

\subsection{Method of Study}

The study followed the semi-experimental approach using an experimental group that learned the English language using blended learning and a control group that learned the same material using the traditional method.

\subsection{Study Sample}

The research sample consisted of two main groups chosen randomly, and the researcher was keen that the two groups were of the same school level, the same school, and the same curriculum, and the groups were divided as follows:

- The experimental group, consisting of (35) students who were taught with the blended learning strategy.

- The control group, consisting of (35) students who were taught with the traditional learning strategy.

\subsection{Study Tool}

To achieve the objectives of the study, the researcher prepared an achievement test and made sure of its validity and reliability as follows:

1. Determining the purpose of the test: This test aimed to measure the scientific aspect of the English language subject for the fifth grade of elementary school, and the number of vocabularies reached (25) items.

2. Test control: to ensure the validity and reliability of the test, the researcher did the following:

- Validity of the test: To verify the validity of the test, the researcher presented the test to a group of specialists in the English language subject to know their performance on the test; amendments were made according to the opinions of the arbitrators. 
- Stability of the test: The stability of the achievement test was confirmed by the internal consistency coefficient (Alpha) of Cronbach, using the statistical software package (SPSS), and it reached (0.627), which indicates that the test vocabulary is interrelated and has stability and internal consistency, and therefore, it can be relied upon for scientific research purposes.

\subsection{Study Results}

Table (2-3). Arithmetic Means for the Direct Achievement Test

\begin{tabular}{|c|c|c|c|c|}
\hline Group & Arithmetic Means & Value (F) & Degree of Freedom & Level of Significance \\
\hline Experimental Group & 14.8 & 65.42 & 72.2 & 0.000 \\
\hline Control Group & 9.16 & & & \\
\hline
\end{tabular}

It can be seen from the previous table that the value of $(F)$ is (65.42) at degrees of freedom of (72.2) and the computer-calculated significance for it is $(0.000)$, and since this calculated significance is less than $(0.05)$, the value of $(\mathrm{F})$ is significant at the level of $(0.05)$, where there is a statistically significant difference at a level of significance (0.05), indicating that the average grades of students in the direct post-achievement test are in favors of the group with the highest arithmetic mean, and thus the experimental group that studied the blended learning method is favorable.

Table (3-3). Arithmetic Means for the Deferred Achievement Test

\begin{tabular}{|c|c|c|c|c|}
\hline Group & Arithmetic Means & Value (F) & Degree of Freedom & Level of Significance \\
\cline { 1 - 2 } Experimental Group & 16.04 & \multirow{2}{*}{49.18} & 72.2 & 0.000 \\
\hline Control Group & 13.32 & & & \\
\hline
\end{tabular}

It is evident from the previous table that the value of $(F)$ is (49.18) at degrees of freedom of (72.2) and the computer-calculated significance for it is (0.000), since this calculated significance is less than (0.05), the value of (F) is significant at the level of (0.05), where there is a statistically significant difference at a level of significance (0.05), indicating that the average grades of students in the deferred achievement test are in favour of the group with the highest arithmetic mean, and thus it is in favor of the experimental group that studied the blended learning method.

The results of the statistical analysis indicated that there are statistically significant differences in the achievement of the primary stage/fifth grade in favor of the experimental group that was taught the English language curriculum using blended learning,

\section{Conclusion}

There is a positive effect of blended learning on the educational process and on achievement of the primary stage. The reason for these positive results is due to the fact that the blended learning strategy is based on a number of positive elements in the educational process, and these elements are represented by: achieving effective integration between the various means of transferring information in the teaching and learning environments as a result of adopting the systemic approach in using the blended technology with the best features of face-to-face interaction, providing face-to-face communication, which increases the interaction between the student and the teacher, the students among each other, and between the students and the content, sufficient flexibility to meet the individual needs and learning styles of learners at different levels, ages, and times, focuses on aspects of knowledge and skill without affecting one another, maintains the link between the student and the teacher, which is the basis on which the educational process is based, increases the ability of learners to self-learn and manage their learning, increases motivation towards learning and creating fun in learning through the use of multimedia, easy access to educational content anytime and anywhere, and develops teamwork and participation in the process. The study recommends the necessity of applying the blended learning strategy for its effectiveness in students' educational achievement, improving motivation to learn, observing the rules of the blended educational process, and training faculty members on applying blended learning.

\section{References}

Abu Musa, M., \& Al-Sous, S. (2010). The Impact of a Blended Learning Training Program on Teachers' Ability to 
Design and Produce Educational Multimedia. Arab Open University, Jordan.

Al-Aifari, M. (2010). The Effect of Using Blended Education on the Acquisition of Basic Eighth Grade Pupils in Public and Private Schools in Amanat Al-Asimah of Social Concepts and Their Attitudes Towards It. Unpublished PhD Dissertation, University of Aden, Yemen.

Al-Dasouqi, W. (2016). The Effect of a Structured Peer Education Strategy Based on Blended Learning on Developing Some InDesign Program Skills and Problem-Solving Skills among Professional Diploma Students e-Learning. Arab Studies in Education and Psychology, 78, 71-104.

Al-Feki, A. (2011). Blended Learning, Instructional Design, Multimedia, Innovative Thinking. Amman, Jordan: House of Culture and Publishing.

Al-Saeed, K. H. (2017). The Effectiveness of Blended Learning in the Achievement and Motivation of Students of the Teaching Technologies Course at Taibah University. Journal of Educational and Psychological Sciences, $11(1), 237-283$.

Al-Shammari, M. (2007). The Effect of Using Blended Learning in Teaching Geography on the Achievement of Middle-Grade Third-Grade Students in Hafar Al-Batin Governorate and Their Attitudes Towards It. Unpublished PhD Dissertation, University of Jordan, Jordan.

Ausburn, L. (2004). Course Design Elements Most Valued by Adult Learners in Blended Online Education Environments: An American Perspective. Educational Media International, 41(4), 327-337. https://doi.org/10.1080/0952398042000314820

Awad, H. (2010). The Effect of Using Blended Education on Learners' Achievement at Al-Quds Open University. Journal of Educational Sciences, 13(2), 12-20.

Beavers, K. (2014). Mind and Concept Mapping. Tips and Trends. Instructional Technologies Committee. Association of College and Research Libraries and American Library Association.

Boyle, T. (2005). A Dynamic, Systematic Method for Developing Blended Learning. Education, Communication \& Information, 5(3), 221-232. https://doi.org/10.1080/14636310500350422

Brame, C. (2013). Flipping the Classroom. Vanderbilt University Center for Teaching. Retrieved from http://cft.vanderbilt.edu/guides-sub-pages/flipping-the-classroom/

Clement, M., Vandeput, L., \& Osaer, T. (2016). Blended Learning Design: A Shared Experience. Procedia-Social and Behavioural Sciences, 228, 582-586. https://doi.org/10.1016/j.sbspro.2016.07.089

Creason, L. (2005). Relationships among Community College Developmental Reading Students' Self-Regulated Learning, Internet Self-Efficacy, Reading Ability and Achievement in Blended/Hybrid and Traditional Classes: A Program Review. Unpublished PhD Dissertation, University of Missouri, United States of America.

Dikeidek, B. (2011). Lessons Learned from Experiences in Blended Learning at Al-Quds University.

Heinze, A., \& Procter, C. (2004). Reflections on the Use of Blended Learning. Proceedings of Education in a Changing Environment. University of Salford, Education Development Unit, United Kingdom. Retrieved from http://usir.salford.ac.uk/id/eprint/1658/1/

Huang, R., \& Zhou, Y. (2006). Designing Blended Learning Focused on Knowledge Category and Learning Activities. The Handbook of Blended Learning: Global Perspectives, Local Designs, 296-310.

Moukali, K. H. (2012). Factors That Affect Faculty Attitudes Toward Adoption of Technology-Rich Blended Learning. Unpublished PhD Dissertation, University of Kansas, United States of America.

Mustafa, H. (2011). The Effect of Using the Blended Learning on the Achievement of Female Students of Home Economics (Majoring in Cosmetology) for the First Grade of Secondary School and Their Attitudes Towards It. Unpublished Master's Thesis, Middle East University, Amman, Jordan.

Qustandi, S. H. (2007). Modern Patterns in Higher Education: Multimedia E-Learning or Excellent Education. The Sixth Conference of Deans of Faculties of Arts in the Member Universities of the Association of Arab Universities. Seminar on Quality Assurance and Academic Accreditation, Jinan University, Lebanon.

Salem, A. (2004). Education and E-Learning Technology. Riyadh, Saudi Arabia: Al-Rashed Library.

Singh, H. (2003). Building Effective Blended Learning Programs. Educational Technology, 43(6), 51-54.

Smith, T. (2016). New Frontiers in Blended Learning. Retrieved from 
https://www.techlearning.com/resources/new-frontiers-in-blended-learning

Steve, S. (2001). Use Blended Learning to Increase Learner Engagement and Reduce Training Costs. Learning Safari Newsletter, April 2001.

Taha, A. (2015). The Effectiveness of Using Blended Learning in Developing the Skills of Producing Visual Basic.Net Projects among High School Students. Journal of the College of Education, Benha, 26(102), 341-362. https://doi.org/10.1080/09243453.2013.869233

\section{Copyrights}

Copyright for this article is retained by the author(s), with first publication rights granted to the journal.

This is an open-access article distributed under the terms and conditions of the Creative Commons Attribution license (http://creativecommons.org/licenses/by/4.0/). 